\title{
COMPARISON OF AUTONOMIC FUNCTIONS IN MALES AND FEMALES
}

\author{
Megha Kapoor', Varun Malhotra², Neera Goel ${ }^{3}$, Yogesh Tripathi', Shivani Gupta ${ }^{5}$ \\ 1 Demonstrator, Department of Physiology, Government Medical College, Jammu. \\ ${ }^{2}$ Associate Professor, Department of Physiology, AIIMS, Bhopal. \\ ${ }^{3}$ Associate Professor, Department of Physiology, Santosh Medical College, Ghaziabad, U. P. \\ 4 Professor, Department of Physiology, Santosh Medical College, Ghaziabad, U. P. \\ ${ }_{5}^{5}$ MBBS Student, Santosh Medical College, Ghaziabad, U. P.
}

\section{ABSTRACT}

\section{BACKGROUND}

The Autonomic Nervous System [ANS] is an extensive neural network, whose main role is to regulate the milieu interior by controlling homeostasis and visceral functions. The efferent autonomic signals are transmitted to various organs of the body through two major subdivisions, Parasympathetic Nervous System [PSNS] and Sympathetic Nervous System [SNS]. Gender differences in the ANS may be present because of the developmental differences or due to the effect of prevailing levels of male and female sex hormones. We evaluated and compared the gender related differences in ANS [Sympathetic and Parasympathetic] in age group of 17 - 25 years.

\section{MATERIALS AND METHODS}

The prospective study was conducted on 200 healthy male and female volunteers of age 17 - 25 years giving an informed consent. For assessing the sympathetic activity, both SBP and DBP and blood pressure response to standing and cold pressor response were taken. For assessing parasympathetic functions, the following tests were done like ECG [with the help of single channel 12 -lead electrocardiograph]. The test done with electrocardiograph include Standing-to-Lying ratio [S/L ratio], $30: 15$ ratio. The data was analysed using computer software MS Excel and SPSS Statistics [Version 20] for Windows.

\section{RESULTS}

The mean SBP of males is $122.14 \pm 5.18 \mathrm{mmHg}$ and mean DBP of males is $80.7 \pm 3.97 \mathrm{mmHg}$, mean SBP of females during menstrual phase is $112.3 \pm 5.18 \mathrm{mmHg}$ and the mean DBP is $71.54 \pm 5.89 \mathrm{mmHg}$. The difference in mean SBP and DBP in males and females during menstrual phase is statistically highly significant $(\mathrm{p}<0.001)$. The mean rise in DBP in cold pressor of males is 4.96 $\pm 2.96 \mathrm{mmHg}$ and of females during menstrual phase is $3.16 \pm 2.76 \mathrm{mmHg}$. There is statistically highly significant difference in mean rise in SBP $(p<0.001)$, while the difference in mean rise in DBP is only statistically significant $(p<0.05)$ in males and females during menstrual phase. The mean standing/ lying ratio (S/L Ratio) in males is $1.23 \pm 0.2$ and in females during menstrual phase is $1.29 \pm 0.08$ and $30: 15$ ratio in males is $1.08 \pm 0.12$ and in females during menstrual phase is $1.21 \pm 0.09$. These differences are also statistically highly significant $(\mathrm{p}<0.05)$.

\section{CONCLUSION}

This study revealed that there is predominant sympathetic activity in males as compared to females due to higher levels of testosterone and catecholamines in them. At all ages, women were found to have reduced sympathetic activity and enhanced parasympathetic activity and plasma norepinephrine levels relative to men.

\section{KEYWORDS}

Autonomic Nervous System, Cold Pressor Test, SBP, DBP, S/L Ratio.

HOW TO CITE THIS ARTICLE: Kapoor M, Malhotra V, Goel N, et al. Comparison of autonomic functions in males and females. J. Evolution Med. Dent. Sci. 2017;6(92):6602-6606, DOI: 10.14260/jemds/2017/1431

\section{BACKGROUND \\ The progress of knowledge of autonomic nervous system [ANS] has been continuous for at least the last 250 years. The ANS is an extensive neural network, whose main role is to regulate the milieu interior by controlling homeostasis and visceral functions. ${ }^{1}$ This system plays an important role to control arterial pressure, gastrointestinal secretions and motility, urinary bladder emptying, sweating, body}

'Financial or Other Competing Interest': None.

Submission 26-10-2017, Peer Review 19-11-2017,

Acceptance 25-11-2017, Published 04-12-2017.

Corresponding Author:

Dr. Megha Kapoor,

Demonstrator,

Department of Physiology,

Government Medical College, Jammu.

E-mail: maddy654@gmail.com

DOI: $10.14260 /$ jemds $/ 2017 / 1431$ temperature and many other activities. The efferent autonomic signals are transmitted to various organs of the body through two major subdivisions, Parasympathetic Nervous System [PSNS] and Sympathetic Nervous System [SNS]. ${ }^{2}$ Gender differences in the ANS may be present because of the developmental differences or due to the effect of prevailing levels of male and female sex hormones. In addition to changes in the reproductive system, there occurs a regular fluctuation in numerous functions affecting all body systems. These can be physical, psychological or behavioural. Over the past 10 years, differences between the physiology of men and women have been recognised with respect to the normal cardiovascular physiology as well as with respect to the incidence, severity and co-morbidities of obesity, diabetes and cardiovascular diseases. Physiologically, the functional differences as well as the similarities are of utmost importance, as they provide fundamental insight into the mechanisms regulating the integrated functions of the intact 
organism..$^{3}$ At all ages, women were found to have reduced sympathetic activity and enhanced parasympathetic activity relative to men. Similarly, men were found to have higher plasma norepinephrine levels than women. ${ }^{4}$ Our knowledge of the ANS has increased with an understanding of Heart Rate Variability [HRV], a non-invasive measure of cardiac autonomic control. The extent to which HRV is influenced by the sex of the subject has been contentious with some studies reporting significantly greater, some reporting significantly lower or similar HRV for females as compared to males. Discrepancies in the studies reporting male/ female differences in HRV may be a result of the time of the menstrual cycle for females, at which the HRV comparison was made with the males. ${ }^{5}$ Although, researchers from myriad of disciplines are beginning to appreciate the importance of considering sex differences in the design and interpretation of their studies, this is an area that is full of potential pitfalls.

\section{Aims and Objectives}

To evaluate and compare the gender related physiological differences in ANS [Sympathetic and Parasympathetic] in age group of 17 - 25 years.

\section{MATERIALS AND METHODS}

\section{Study Design}

Prospective study.

\section{Study Population}

The study was conducted on 200 healthy male and female volunteer medical, dental and nursing students to meet the required sample size. The sample size estimation was also done at conveniences.

\section{Place of Study}

The study was conducted in the Department of Physiology of Santosh Medical College, Ghaziabad.

\section{Duration of Study}

The study was conducted from July 2015 - July 2016.

\section{Methodology}

After detailing the Purpose and Methods of the Study, all Eligible Candidates were allocated into Two Groups-

a) Group 1 comprised of young healthy male volunteers.

b) Group 2 comprised of young healthy female volunteers undergoing through menstrual phase.

\section{The Inclusion Criteria for Eligible Candidates Include-}

1. Healthy males.

2. Healthy females with regular menstrual cycle and undergoing menstrual phase.

3. Age $17-25$ years.

4. Subjects willing to participate in the study.

5. Informed consent.

Certain physical parameters were noted in each subject which include age, height [in $\mathrm{cms}$ ], weight [in $\mathrm{kg}$ ], BMI $\left[\mathrm{kg} / \mathrm{m}^{2}\right.$, calculated by formula weight [in $\left.\mathrm{kg}\right] /$ height ${ }^{2}\left[\mathrm{in} \mathrm{m}^{2}\right]$ in males and females. After recording their physical parameters, all the subjects underwent the following tests to assess ANS activity. For assessing the sympathetic activity, the following tests were done like blood pressure [with the help of sphygmomanometer, three recordings of both SBP and DBP were taken and then their mean value is taken as the actual DBP and SBP], blood pressure response to standing [orthostasis], cold pressor response [by placing the subject's hand up to the distal crease at the wrist in cold water at temperature of $4^{\circ} \mathrm{C}$ for 2 minutes]. For assessing parasympathetic functions, the following tests were done like ECG [with the help of single channel 12-lead electrocardiograph]. The test done with electrocardiograph include Standing-to-Lying ratio [S/L ratio], calculated as [Longest R-R interval during the 5 beats before lying down/ Shortest R-R interval during the 10 beats after lying down], 6 30: 15 ratio, calculated as [R-R interval at beat $30^{\text {th }} / \mathrm{R}-\mathrm{R}$ interval at beat $15^{\text {th }}$ of the ECG recorded immediately upon standing]. ${ }^{7}$ The quantitative data was analysed using computer software MS Excel and SPSS Statistics [Version 20] for Windows. All parameters were reported as mean and standard deviation. The statistical difference in mean values was tested using unpaired student's ' $\mathrm{t}$ ' test. A p-value $<0.05$ was considered statistically significant, $p$-value $>0.05$ was considered non-significant and p-value of $<0.001$ was considered as highly significant.

Study by convenient sampling technique since the duration of the study was short duration. The sample size was selected by convenience sampling technique.

\section{RESULTS}

The following observations were made from the study-

\begin{tabular}{|c|c|c|c|c|c|}
\hline \multirow{2}{*}{$\begin{array}{l}\text { Blood } \\
\text { Pressure }\end{array}$} & \multirow{2}{*}{$\begin{array}{l}\text { Males } \\
\text { Mean } \pm \\
\text { SD }\end{array}$} & \multirow{2}{*}{$\begin{array}{c}\text { Females } \\
\text { during } \\
\text { Menstrual } \\
\text { Phase } \\
\text { Mean } \pm \text { SD }\end{array}$} & \multicolumn{2}{|c|}{$\begin{array}{l}\text { Statistical } \\
\text { Analysis } \\
\text { ('t' test) }\end{array}$} & \multirow[t]{2}{*}{$\begin{array}{l}\text { Statistical } \\
\text { Inference }\end{array}$} \\
\hline & & & ' $\mathbf{t}^{\prime} \mathbf{t}$ & & \\
\hline SBP & 5 & $\begin{array}{c}112.3 \pm \\
5.18\end{array}$ & 13.927 & \multirow{2}{*}{$\begin{array}{l}<0.001 \\
<0.001\end{array}$} & Sig \\
\hline DB & & & 12.894 & & $\begin{array}{l}\mathrm{Hi} \\
\text { Signi }\end{array}$ \\
\hline \multicolumn{6}{|c|}{$\begin{array}{c}\text { Table 1. Relationship of Mean Systolic Blood Pressure and } \\
\text { Mean Diastolic Blood Pressure of Females undergoing } \\
\text { Menstrual Phase and Males }\end{array}$} \\
\hline
\end{tabular}

Table 1 reveals that the mean SBP of males is $122.14 \pm$ $5.18 \mathrm{mmHg}$ and of females during menstrual phase is $112.3 \pm$ $5.18 \mathrm{mmHg}$. The mean DBP of males is $80.7 \pm 3.97 \mathrm{mmHg}$ and of females during menstrual phase is $71.54 \pm 5.89 \mathrm{mmHg}$. The difference in mean SBP and DBP in males and females during menstrual phase is statistically highly significant $(p<0.001)$.

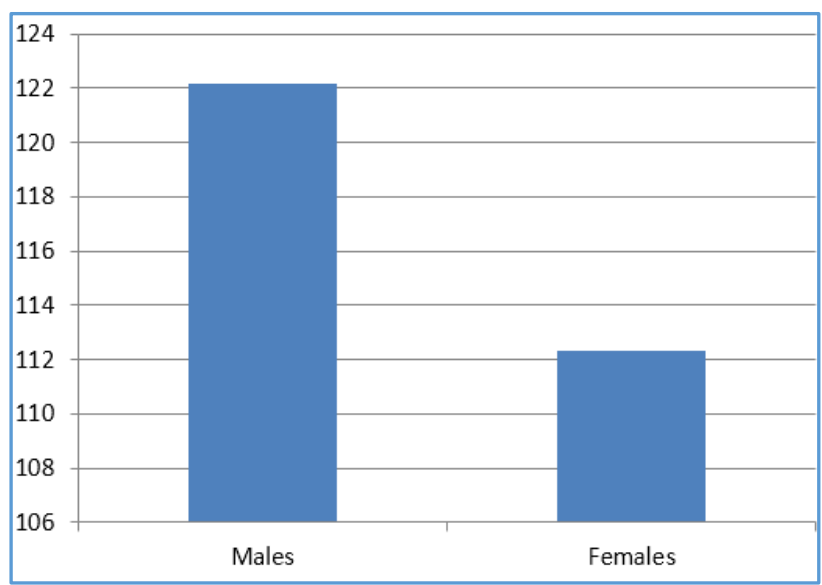




\begin{tabular}{|c|c|c|c|c|c|}
\hline \multirow{2}{*}{$\begin{array}{c}\text { Blood } \\
\text { Pressure } \\
\text { Response } \\
\text { to } \\
\text { Standing }\end{array}$} & \multirow{2}{*}{$\begin{array}{c}\text { Males } \\
\text { Mean + } \\
\text { SD }\end{array}$} & \multirow{2}{*}{\begin{tabular}{|c} 
Females \\
during \\
Menstrual \\
Phase \\
Mean + \\
SD
\end{tabular}} & \multicolumn{2}{|c|}{$\begin{array}{c}\text { Statistical } \\
\text { Analysis } \\
\text { ('t' test) }\end{array}$} & \multirow{2}{*}{$\begin{array}{l}\text { Statistical } \\
\text { Inference }\end{array}$} \\
\hline & & & 't' test & 'p' value & \\
\hline SBP & $\begin{array}{c}-4.72+ \\
3.26 \\
\end{array}$ & $\begin{array}{c}-4.5+ \\
3.56\end{array}$ & $\begin{array}{c}- \\
0.427 \\
\end{array}$ & $>0.05$ & $\begin{array}{c}\text { Non- } \\
\text { Significant }\end{array}$ \\
\hline DBP & $\begin{array}{l}3.1+ \\
3.17\end{array}$ & $\begin{array}{c}1.68+ \\
1.81\end{array}$ & 3.888 & $<0.0012$ & $\begin{array}{c}\text { Highly } \\
\text { Significant }\end{array}$ \\
\hline
\end{tabular}

Table 2. Relationship of Mean Systolic Blood Pressure Response and Diastolic Blood Pressure Response to Standing between Females during Menstrual Phase and Males

Table 2 depicts that the mean fall in SBP on standing of males is $-4.72 \pm 3.26 \mathrm{mmHg}$ and mean fall in SBP on standing of females during menstrual phase is $-4.5 \pm 3.56 \mathrm{mmHg}$. The difference between the two groups is statistically nonsignificant $(\mathrm{p}>0.05)$.

Table 2a shows that the mean rise in DBP on standing of males is $3.1 \pm 3.17 \mathrm{mmHg}$ and mean rise in DBP on standing of females during menstrual phase is $1.68 \pm 1.81 \mathrm{mmHg}$. This difference is statistically highly significant $(p<0.001)$.
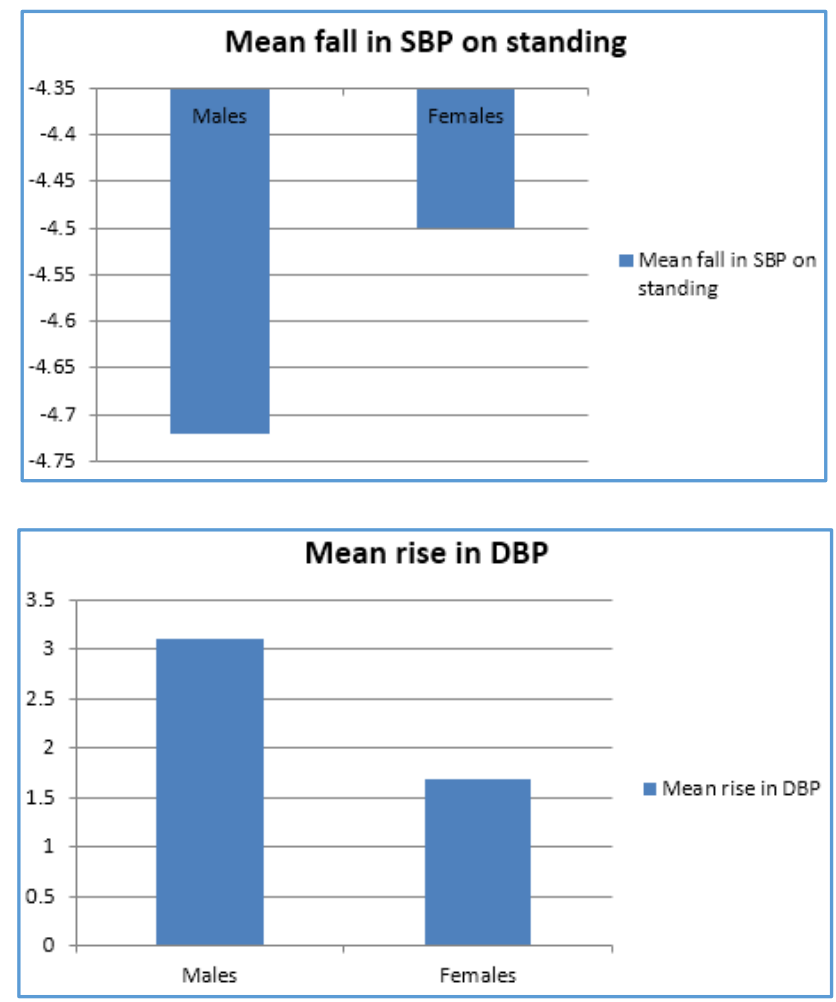

\begin{tabular}{|c|c|c|c|c|c|}
\hline \multirow{2}{*}{\begin{tabular}{|c|} 
Blood \\
Pressure \\
Response \\
to Cold \\
Pressor \\
Test \\
\end{tabular}} & \multirow{2}{*}{$\begin{array}{c}\text { Males } \\
\text { Mean } \pm \\
\text { SD }\end{array}$} & \multirow{2}{*}{\begin{tabular}{|c|} 
Females \\
during \\
Menstrual \\
Phase \\
Mean \pm \\
SD \\
\end{tabular}} & \multicolumn{2}{|c|}{$\begin{array}{c}\text { Statistical } \\
\text { Analysis } \\
\text { ('t' test) }\end{array}$} & \multirow{2}{*}{ 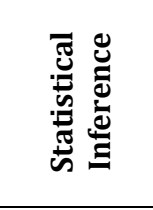 } \\
\hline & & & 't' test & 'p' value & \\
\hline SBP & $\begin{array}{c}9.32 \pm \\
2.46\end{array}$ & $11 \pm 3.99$ & -3.664 & $<0.001$ & $\begin{array}{c}\text { Highly } \\
\text { Significant }\end{array}$ \\
\hline DBP & $\begin{array}{l}4.96 \pm \\
2.96\end{array}$ & $\begin{array}{c}3.16 \pm \\
2.76\end{array}$ & 2.15 & $<0.05$ & Sign \\
\hline
\end{tabular}

Table 3. Relationship of Mean Systolic Blood Pressure Response and Diastolic Blood Pressure Response to Cold Pressor Test between Females during Menstrual Phase and Males
Table 3 reveals that the mean rise in SBP in cold pressor test in males is $9.32 \pm 2.46 \mathrm{mmHg}$ and in females during menstrual phase is $11 \pm 3.99 \mathrm{mmHg}$. Table 3 also depicts that the mean rise in DBP in cold pressor of males is $4.96 \pm 2.96$ $\mathrm{mmHg}$ and of females during menstrual phase is $3.16 \pm 2.76$ mmHg. There is statistically highly significant difference in mean rise in SBP $(\mathrm{p}<0.001)$, while the difference in mean rise in DBP is only statistically significant $(\mathrm{p}<0.05)$ in males and females during menstrual phase.
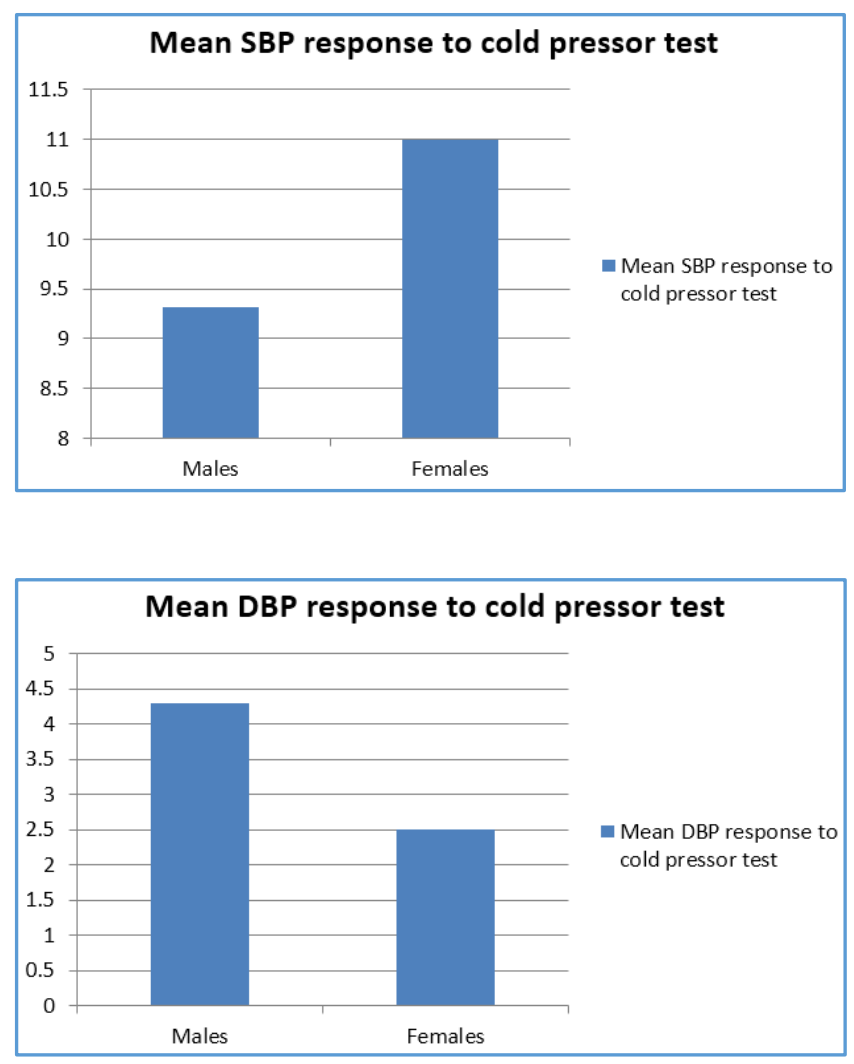

\begin{tabular}{|c|c|c|c|c|c|}
\hline \multirow[t]{2}{*}{ Ratio } & \multirow{2}{*}{$\begin{array}{c}\text { Males } \\
\text { Mean } \pm \text { SD }\end{array}$} & \multirow{2}{*}{$\begin{array}{c}\text { Females } \\
\text { during } \\
\text { Menstrual } \\
\text { Phase } \\
\text { Mean } \pm \text { SD }\end{array}$} & \multicolumn{2}{|c|}{$\begin{array}{c}\text { Statistical } \\
\text { Analysis } \\
\text { ('t' test) }\end{array}$} & \multirow{2}{*}{$\begin{array}{l}\text { Statistical } \\
\text { Inference }\end{array}$} \\
\hline & & & ' $t$ ' test & $\begin{array}{c}\text { 'p' } \\
\text { value }\end{array}$ & \\
\hline S/L & $1.32 \pm 0.2$ & $1.29 \pm 0.08$ & -2.689 & $<0.05$ & Significant \\
\hline $30: 15$ & $1.08 \pm 0.12$ & $1.21 \pm 0.09$ & -8.813 & $<0.001$ & $\begin{array}{c}\text { Highly } \\
\text { Significan }\end{array}$ \\
\hline
\end{tabular}

Table 4. Overall Comparison of various Parasympathetic Function Tests between Females during Menstrual Phase and Males

Table 4 depicts that the mean standing/ lying ratio (S/L Ratio) in Males is $1.23 \pm 0.2$ and in females during menstrual phase is $1.29 \pm 0.08$. There is statistically significant difference between males and females during menstrual phase $(\mathrm{p}<0.05)$. Mean 30: 15 ratio in males is $1.08 \pm 0.12$ and in females during menstrual phase is $1.21 \pm 0.09$. This difference is also statistically highly significant $(\mathrm{p}<0.001)$. 

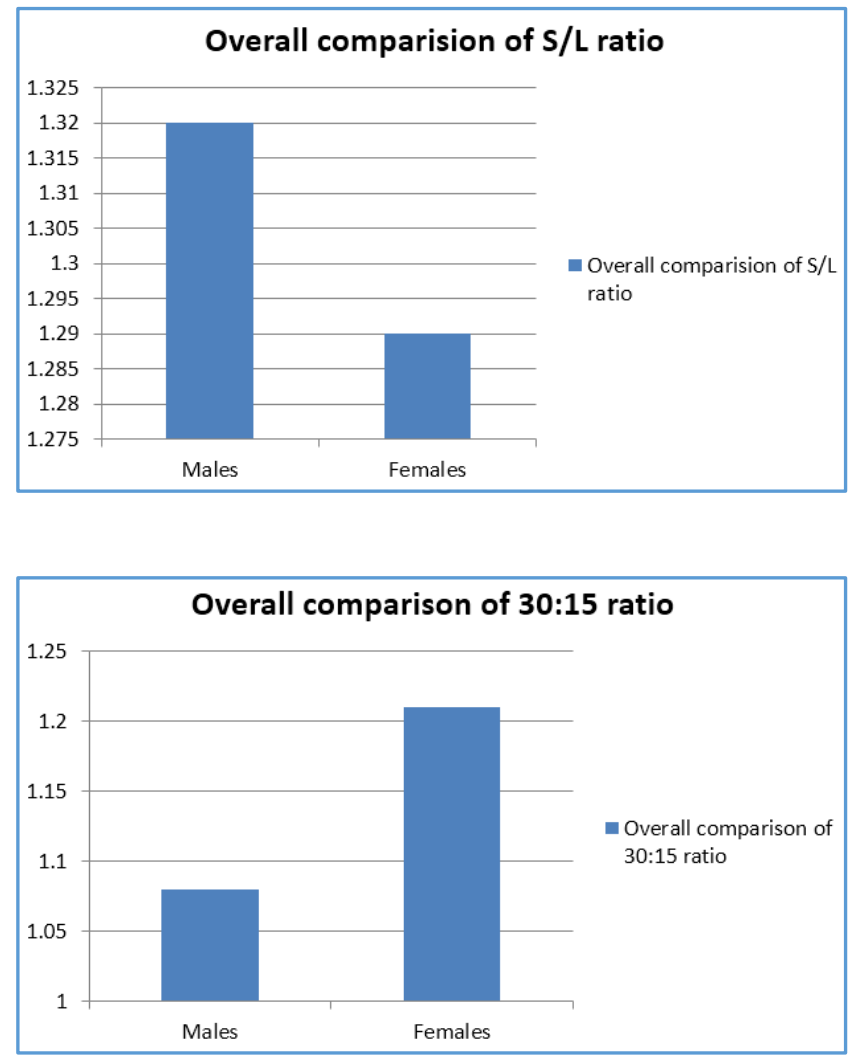

\section{DISCUSSION}

Cardiovascular autonomic reflexes are essential for the maintenance of arterial blood pressure during the orthostatic stress adopting a standing posture and for preventing wide fluctuations of arterial BP in response to stress, exercise and other adaptive responses. ${ }^{8}$ In the present study, it was assessed that the women have lower tonic ANS support of BP and less effective baroreflex buffering [BRB] of BP than men. It was shown that women had lower baseline SBP and plasma catecholamine concentration than men $[p<0.05] .{ }^{9}$ It was further mentioned that there is a risk of hypertension in women as compared to young men and as age advances both blood pressure and the risk of hypertension increase in both the sexes. This occurs most strikingly in women after menopause. 10 When the blood pressure response to standing [orthostasis] was observed, it was found that women have a less pronounced sympathetic response to stress and therefore less vasoconstrictor activity upon standing, ${ }^{11,12}$ in addition to smaller stroke volume leading to lower postural blood pressure response. ${ }^{13}$ The association of autonomic functions with gender was analysed and was found that the systolic blood pressure values were lower in females in cold pressor response as compared to age matched males, 14 which was against our results. Parasympathetic activity is assessed by measuring baroreflex control of heart rate during manoeuvres, which modify blood pressure. These tests measure a complex reflex arc reflecting a 'beat to beat' balance of sympathetic and parasympathetic activity, which can be easily altered by physical and emotional stress. ${ }^{15}$ When a subject lies down from the standing position, there is an initial brief rise due to rapid decrease of vagal tone and later fall because of increase of vagal tone ${ }^{16}$ in Standing-Lying ratio [S/L]. The 30: 15 ratio demonstrates that the females during initial phase of menstrual cycle have higher sympathetic nervous activity as compared to males. No significant dependence on gender was found in this study, although blood pressure responses to handgrip tended to be slightly greater in men than in women. ${ }^{17}$

\section{Limitation of the Study}

Due to short duration of study, convenience sampling technique was followed. Thus, sampling size was also calculated by convenience. The results of the study cannot be generalised due to the potential bias resulting from the sampling technique and sample size estimation.

\section{CONCLUSION}

This study revealed that there is predominant sympathetic activity in males in comparison to females, probably due to high testosterone and catecholamine levels higher in males as compared to females. Gender differences in the ANS may be present because of developmental differences or due to the effects of prevailing levels of male/ female sex hormones. The ANS is of importance in the natural history and treatment of a number of pathophysiological states involving the cardiovascular system. These include hypertension and diseases of the vasculature as well as the myocardial ischaemia and cardiac arrhythmias. Both short and long-term prognosis for MI are worse for women than men, whereas women with non-ischaemic cardiomyopathy have improved survival. In addition to the well-known difference in age of presentation of coronary heart disease, women are more likely to suffer from Raynaud's phenomenon, and to experience presyncopal or syncopal episodes. Therefore, an appreciation of gender differences is the structure and function of the ANS is important to a full understanding of a number of common and important clinical presentations.

\section{REFERENCES}

[1] Sandroni P. Testing the autonomic nervous system. Technical Corner from IASP Newsletter, NovemberDecember 1998.

[2] Hall JE. The autonomic nervous system and the adrenal medulla. Guyton and Hall textbook of medical physiology. 12th edn. New Delhi, India, Elseveir, 2011:729-39.

[3] Huxley VH. Sex and the cardiovascular system: the intriguing tale of how women and men regulate cardiovascular function differently. Adv Physiol Educ 2007;31(1):17-22.

[4] Geelen G, Laitinen T, Hartikainen J, et al. Gender influence on vasoactive hormones at rest and during a 70 degree head-up tilt in healthy humans. J Appl Physiol 2002;92(4):1401-8.

[5] Leicht AS, Hirning DA, Allen GD. Heart rate variability and endogenous sex hormones during the menstrual cycle in young women. Exp Physiol 2003;88(3):441-6.

[6] Rodrigues EA, Ewing DJ. Immediate heart rate response to lying down: simple test for cardiac parasympathetic damage in diabetics. $\mathrm{Br}$ Med J 1983;287(6395):800.

[7] Ewing DJ, Campbell IW, Murray A, et al. Immediate heart-rate response to standing: simple test for autonomic neuropathy in diabetes. $\mathrm{Br}$ Med J 1978;1(6106):145-7. 


\section{Jemds.com}

[8] Benarroch EE. Functional anatomy of the central autonomic network. In: Benarroch EE, (eds). Central autonomic network: functional organization and clinical correlations. Armonk: Futura Publishing Co. Inc.; 1997:29-59.

[9] Christou DD, Jones PP, Jordan J, et al. Women have lower tonic autonomic support of arterial blood pressure and less effective baroreflex buffering than men. Circulation 2005;111(4):494-8.

[10] Hart EC, Joyner MJ, Wallin BG, et al. Sex, ageing and resting blood pressure: gaining insights from the integrated balance of neural and hemodynamic factors. J Physiol 2012;590(9):2069-79.

[11] Convertino VA. Gender differences in autonomic functions associated with blood pressure regulation. Am J Physiol 1998;275(6 Pt 2):R1909-20.

[12] Shoemaker JK, Hogeman CS, Khan M, et al. Gender affects sympathetic and hemodynamic response to postural stress. Am J Physiol Heart Circ Physiol 2001;281(5):H2028-35.

\section{Original Research Article}

[13] Fu Q, Arbab-Zadeh A, Perhonen MA, et al. Hemodynamics of orthostatic intolerance: implications for gender differences. Am J Physiol Heart Circ Physiol 2004;286(1):H449-57.

[14] Gandhi DK, Singh J. Gender and autonomic nervous system. Indian J Fundam Appl Life Sci 2011;1(4):1729.

[15] Low PA, Pfeifer MA. Standardization of autonomic function. Quoted by: Low PA. In: Clinical autonomic disorders. $2^{\text {nd }}$ edn. Philadelphia, Lippincott-Raven, 1997:287-95.

[16] Jain AK. Autonomic nervous system testing. Manual of practical physiology. $3^{\text {rd }}$ edn. Himachal Pradesh, India. Arya Publications, 2008:279-85.

[17] Gautschy B, Weidmann P, Gnadinger MP. Autonomic function tests as related to age and gender in normal man. Klin Wochenschr 1986;64(11):499-505. 